\title{
First hematopoietic stem cell transplantation in a child with late infantile Krabbe disease in Poland
}

\author{
Izabella Miśkiewicz-Migoń, Justyna Miśkiewicz-Bujna, Monika Mielcarek-Siedziuk, \\ Jowita Frączkiewicz, Ewa Gorczyńska, Krzysztof Kałwak
}

Department of Pediatric Bone Marrow Transplantation, Oncology and Hematology, Wroclaw Medical University, Wroclaw, Poland

\section{ABSTRACT}

Krabbe disease (KD) is a lysosomal storage disorder, caused by a deficiency of galactocerebrosidase (GALC) or a mutation in the prosaposin gene, which leads to psychosine accumulation. Consequently, demyelination and degradation of the nervous system occur. Newborns with early infantile Krabbe disease usually present with poor feeding, irritability, hypertonicity, deafness and visual impairment. They usually die, unless transplanted with hematopoietic stem cells (HSC) during the 1st month of life. Patients with late form KD have heterogeneous symptoms, like ataxia or spastic paresis followed by slow progression. Therapeutic options are limited and hematopoietic stem cell transplantation (HSCT) remains the only life-saving method. In this report, we describe the first HSCT in late-infantile Krabbe disease in Poland. The post-transplant period was complicated by graft versus host disease (GvHD), veno-occlusive disease (VOD), mucositis and impairment of renal function. The 5-year follow-up was uneventful, confirming clinical efficacy of the HSCT.

\section{KEY WORDS:}

hematopoietic stem cell transplantation, globoid cell leukodystrophy, Krabbe disease, lysosomal storage disorders.

\section{INTRODUCTION}

Krabbe disease (KD), also known as globoid cell leukodystrophy, is a rare, inherited autosomal recessive lysosomal storage disorder. It has an estimated prevalence of 1 in 100000 births [1]. Krabbe disease is caused mostly by a mutation in the galactocerebrosidase gene (chromosome 14q31), which leads to a deficiency of galactocerebrosidase (GALC) and rarely by a mutation in the prosaposin gene (10q21-q22), that codes saposin A, which is crucial for activation of GALC [2]. GALC is required for the hydrolysis of psychosine and galactosylceramide. Therefore, a deficiency of GALC leads to psychosine accumulation with demyelination and degradation of the central and peripheral nervous system [3]. Based on the age at the onset the forms can be described as: an infantile KD (with subtypes of early-infantile dis- ease with the age of onset below 6 months and late-infantile disease with the age of onset within 6-36 months), a juvenile-onset form and an adult-onset form $[3,4]$. The most common form is the infantile KD which accounts for approximately $90 \%$ of KD cases [4]. The symptoms of the early-infantile form are poor feeding, irritability, hypertonicity, visual and hearing impairment, seizures and the course is characterized by rapid progression with death within 2-3 years without treatment [5-7]. The late-infantile form of KD is clinically heterogeneous and characterized by slow progression in which ataxia or spastic paresis may occur. Allogeneic hematopoietic stem cell transplantation (allo-HSCT) is a disease modifying treatment, in which monocyte-macrophages from a donor with normal GALC repopulate the glial cells of the nervous system, leading to inhibition of disease progression $[7,8]$.

\section{ADDRESS FOR CORRESPONDENCE:}

Justyna Miśkiewicz-Bujna, Department of Pediatric Bone Marrow Transplantation, Oncology and Hematology, Wroclaw Medical University, Wroclaw, Poland, e-mail: miskiewicz.justyna@gmail.com 


\section{CASE REPORT}

A 4.5-month old boy with confirmed globoid cell leukodystrophy, past medical history of left renal agenesis, was admitted to the Department of Pediatric Bone Marrow Transplantation, Oncology, and Hematology in Wroclaw for high-dose chemotherapy with subsequent allo-HSCT.

The patient, the third child of healthy parents was born at gestational age 39 weeks with an Apgar score $7 / 8 / 9$ in $1 / 3 / 5$ minute with a birth weight of $4.3 \mathrm{~kg}$. After birth the right Erb-Duchenne palsy and kidney agenesis were diagnosed. The patient's family history was notable for late-infantile KD confirmed in an older brother, who at the age of approximately 16 months presented with delay in motor development, dysfunction in balance and independent walking. The sister was a healthy carrier and both parents were carriers of two different mutations. Due to family history, genetic counseling was performed and heterozygous mutations c. $1700 \mathrm{~A}>\mathrm{C}$ and c. $1157 \mathrm{G}>\mathrm{T}$ in GALC gene were revealed in our patient. Measurement of GALC or magnetic resonance imaging of the central nervous system hadn't been performed before allo-HSCT. The postnatal period was uneventful, including the patient's neuropsychological development.

Conditioning regimen consisted of fludarabine $\left(30 \mathrm{mg} / \mathrm{m}^{2}\right)$, busulfan $(4 \times 4 \times 1 \mathrm{mg} / \mathrm{kg})$ and thiotepa $(2 \times 5 \mathrm{mg} / \mathrm{kg}$ ). Cyclosporin A (from day -1), methotrexate $\left(10 \mathrm{mg} / \mathrm{m}^{2}\right.$ on days $\left.+1,+3,+6\right)$ and antithymocyte globulin (Grafalon ${ }^{\oplus}, 3 \times 10 \mathrm{mg} / \mathrm{kg}$ on days $-3,-2,-1$ ) were implemented for the prevention of graft rejection and GvHD. Bone marrow transplantation from an 9/10 HLA-matched $\left(\mathrm{A}^{*}\right.$-mismatch) unrelated donor was performed with total dose of $12.2 \times 106 \mathrm{CD} 34+$ cells $/ \mathrm{kg}$ infused.

In the posttransplant period hepatomegaly, rising bilirubin from a baseline value up to $2.3 \mathrm{mg} / \mathrm{dl}$, weight gain requiring implementation of furosemide, transfu-

TABLE 1. EBMT diagnostic criteria for hepatic SOS/VOD in children [9]

\begin{tabular}{|l|}
\hline No limitation for time of onset of SOS/VOD \\
The presence of two or more of the following ${ }^{\mathrm{a}}$ : \\
\hline - Unexplained consumptive and transfusion-refractory thrombo- \\
cytopenia \\
- Otherwise unexplained weight gain on three consecutive days \\
despite the use of diuretics or weight gain $>5 \%$ above baseline \\
value \\
- Hepatomegalyc (best if confirmed by imaging) above baseline \\
value \\
- Ascites (best if confirmed by imaging) above baseline value \\
- Rising bilirubin from a baseline value or bilirubin $\geq 2 \mathrm{mg} / \mathrm{dl}$ \\
within $72 \mathrm{~h}$
\end{tabular}

${ }^{a}$ with the exclusion of other potential differential diagnoses

${ }^{b} \geq 1$ weight-adjusted platelet substitution/day to maintain institutional transfusion guidelines 'Suggested: imaging (US, CT or MRI) immediately before HCT to determine baseline value for both hepatomegaly and ascites. sion-refractory thrombocytopenia and peripheral edema occurred. The patient required implementation of vitamin K, transfusions of plasma and cryoprecipitate. Spironolactone, ursodeoxycholic acid (UDCA) and fluid restrictions were also implemented. The patient was diagnosed with severe hepatic sinusoidal obstruction syndrome/veno-occlusive disease (SOS/VOD) based on new Pediatric EBMT criteria (Table 1) on day +19 [9] . Therefore, defibrotide was implemented from day +20 to day +34 .

A rise in urea and creatinine levels from the baseline value were also observed. Impairment of renal function was related to the nephrotoxic effect of cyclosporine. Therefore, diuresis was monitored, a restriction in amino acid intake was recommended and a urinary catheter was inserted. Taking into account the agenesis of the kidney, cyclosporin was withdrawn, steroids $(1 \mathrm{mg} / \mathrm{kg})$ and mycophenolate mofetil (from day $+24 ; 20 \mathrm{mg} / \mathrm{kg}$ ) were administered. On day +35 acute graft versus host disease (aGvHD) of the skin, grade I, occurred with typical manifestations on the trunk and head. Steroids and cyclosporine were administered with success. Due to proper treatment a gradual improvement in renal and liver parameters were observed with a reduction in the abdominal circumference and peripheral edema. The patient was discharged on day +61 without significant adverse events and with full donor chimerism. Normal activity of blood lysosomal enzymes was confirmed at 18 months posttransplant. The patient remains now alive and well 5 years posttransplant without any significant late side-effects or neurological impairment. His neurological development does not differ from an age-matched healthy population.

\section{DISCUSSION}

The diagnosis of $\mathrm{KD}$ remains a challenge for physicians. The only curative option for early and late infantile KD remains allo-HSCT, which should be performed as early as possible, i.e. in the 1st month of life in the most severe early infantile form. Indication for allo-HSCT in late-infantile KD is less clear [10]. Allo-HSCT is the only modifying treatment, which should be performed at an early stage of disease to prevent severe neurological impairment with lapse into a vegetative state [4]. Recent data clearly indicates that allo-HSCT in the case of pre-symptomatic infantile-KD improves the chance of survival [11, 12]. The neurological deterioration can be stopped or in some cases even reveres by allo-HSCT $[13,14]$. Nevertheless, after successful allo-HSCT, motor disabilities such as spasticity and contractures requiring assistive devices or orthotics may persist [15]. In addition, Caniglia et al. described a 4-month-old-girl with an early onset of Krabbe's disease and minimal central nervous system involvement at diagnosis, who died 180 days after the allo-HSCT, with progressive severe neurologic deterioration [16]. Conversely, little 
information is currently available regarding follow-up for patients with a mild form of late-infantile KD. Lim et al. described a 24-year-old woman, who developed first symptoms of the disease at 3 years of age and underwent successful allo-HSCT. During the 84-month follow-up her neurological coordination markedly improved [8].

SOS/VOD is a life-threatening complication after allo-HSCT, with an incidence in children of approximately $20-60 \%$ [9]. Pathophysiology of VOD is associated with sinusoidal endothelium damage with microthrombosis and the activation of cytokines. Consequently, organ impairment occurs, followed by thrombocytopenia, weight gain, hepatomegaly, ascites and an increase in bilirubin value [9]. Our patient had several risk factors associated with an increased risk of VOD/SOS: infant age and busulfan as part of the conditioning regimen [17]. Due to the diagnosis of VOD, the patient was successfully treated with defibrotide, without late effects of this complication.

In our patient, early allo-HSCT resulted in full donor chimerism, normal GALC activity and ceased KD progression. Two heterozygous mutations found in the patient are well known pathogenic mutations leading to globoid-cell leukodystrophy (GLD), but genotype-phenotype correlations are not well established for Krabbe disease. Taking into account the phenotype of an older brother the presented patient had more chance to develop a milder (late infantile) phenotype, which indeed was the case. The patient did not develop any symptoms of GLD until a curative transplant. We expected more to have the patient with phenotype similar to the older brother, but of course we could not exclude a severe early infantile phenotype.

The patient did not develop the severe phenotype, so we had time to give him a chance for a curative allotransplant. This case indicates the importance of prompt diagnosis of this neurologically devastating disease and referral to a transplant center for a potentially effective allo-HSCT. Genetic screening in affected families is a must. All patients with suspicion of early or late infantile KD have to be tested for GALC enzyme activity and KD-associated gene mutations.

\section{DISCLOSURE}

The authors declare no conflict of interest.

\section{REFERENCES}

1. Duffner PK, Barczykowski A, Kay DM, et al. Later onset phenotypes of Krabbe disease: Results of the world-wide registry. Pediatr Neurol 2012; 46: 298-306.

2. Suzuki K, Suzuki Y. Globoid cell leucodystrophy (Krabbe's disease): deficiency of galactocerebroside beta-galactosidase. Proc Natl Acad Sci U S A 1970; 66: 302-309.

3. Bascou N, Derenzo A, Poe MD, et al. A prospective natural history study of Krabbe disease in a patient cohort with onset between 6 months and 3 years of life. Orphanet J Rare Dis 2018; 13: 126.
4. Escolar ML, West T, Dallavecchia A, et al. Clinical management of Krabbe disease. J Neurosci Res 2016; 94: 1118-1125.

5. Puckett RL, Orsini JJ, Pastores GM, et al. Krabbe disease: clinical, biochemical and molecular information on six new patients and successful retrospective diagnosis using stored newborn screening cards. Mol Genet Metab 2012; 105: 126-131.

6. Morse LE, Rosman NP. Myoclonic seizures in Krabbe disease: a unique presentation in late-onset type. Pediatr Neurol 2006; 35 : 154-157.

7. Allewelt $\mathrm{H}$, Taskindoust $\mathrm{M}$, Troy J, et al. Long-term functional outcomes after hematopoietic stem cell transplant for early infantile Krabbe disease. Biol Blood Marrow Transplant 2018; 24: 2233-2238.

8. Lim ZY, Ho AYL, Abrahams S, et al. Sustained neurological improvement following reduced-intensity conditioning allogeneic haematopoietic stem cell transplantation for late-onset Krabbe disease. Bone Marrow Transplant 2008; 41: 831-832.

9. Corbacioglu S, Carreras E, Ansari M, et al. Diagnosis and severity criteria for sinusoidal obstruction syndrome/veno-occlusive disease in pediatric patients: A new classification from the European society for blood and marrow transplantation. Bone Marrow Transplant 2018; 53: 138-145.

10. Sharp ME, Laule C, Nantel S, et al. Stem cell transplantation for adult-onset krabbe disease: report of a case. JIMD Rep 2013; 10: 57-59.

11. McGraw P, Liang L, Escolar M, et al. Krabbe disease treated with hematopoietic stem cell transplantation: Serial assessment of anisotropy measurements - initial experience. Radiology 2005; 236: 221-230.

12. Kwon JM, Matern D, Kurtzberg J, et al. Consensus guidelines for newborn screening, diagnosis and treatment of infantile Krabbe disease. Orphanet J Rare Dis 2018; 13: 30.

13. Krivit W, Shapiro EG, Peters C, et al. Hematopoietic stem-cell transplantation in globoid-cell leukodystrophy. N Engl J Med 1998; 338: 1119-1126.

14. Laule C, Vavasour IM, Shahinfard E, et al. Hematopoietic stem cell transplantation in late-onset Krabbe disease: no evidence of worsening demyelination and axonal loss 4 years post-allograft. J Neuroimaging 2018; 28: 252-255.

15. Wright MD, Poe MD, DeRenzo A, et al. Developmental outcomes of cord blood transplantation for Krabbe disease: A 15-year study. Neurology 2017; 89: 1365-1372.

16. Caniglia M, Rana I, Pinto RM, et al. Allogeneic bone marrow transplantation for infantile globoid-cell leukodystrophy (Krabbe's disease). Pediatr Transplant 2002; 6: 427-431.

17. Dalle JH, Giralt SA. Hepatic veno-occlusive disease after hematopoietic stem cell transplantation: risk factors and stratification, prophylaxis, and treatment. Biol Blood Marrow Transplant 2016; 22: 400-409. 